\title{
EEG (Electroencephalography) Abnormality in First Episode Mania: Is It Trait or State?
}

\author{
Sermin Kesebir, Sertaç Güven, Elif Tatlıdil Yaylacı, Özgür Bilgin Topçuoğlu, Merih Altıntaş \\ Erenköy Mental and Neurological Disease Training and Research Hospital, İstanbul, Turkey
}

\begin{abstract}
The aim of this study is to investigate the frequency of abnormal EEG (electroencephalography) findings in first episode mania and to determine whether EEG abnormality improves at the subsequent remission period. The secondary, to compare cases with or without abnormal EEG findings with regard to clinical characteristics of BD (bipolar disorder). In the present study, 86 consecutive first attack mania cases between the ages of 18-65 diagnosed as BD, manic episode according to DSM-IV who referred to our outpatient clinic or emergency service whose informed consent form was signed by first degree relatives were evaluated. Inclusion criteria were not having previous depressive episode, absence of any neurologic disorder, especially epilepsy, absence of history head trauma, and/or loss of consciousness and were not using any drugs which can influence electroenecepholafraphic activity before EEG (antiepileptic, anxiolytic, antidepressant, and antipsychotics). Diagnostic interviews were made with SCID-I (DSM-IV Structured Clinical Interview) and information on disease was recorded with SKIP-TURK (Mood Disorder Diagnosis and Follow-up Form). EEG recordings were made with digital EEG device in 16 channels. EEG abnormality is more frequent in mania than remission period $(p=0.022)$ and occurs at the rate of $28.7 \%$. All cases with continuing abnormal EEG findings in remission period are women. In cases with continuing EEG abnormality, the age of menarche is smaller $(p=0.032)$ but family history is less frequent ( $p=0.008$ ). Childhood trauma and history of suicide attempt is more frequent in cases with abnormal EEG in remission period as well $(p<0.001$ and 0.005$)$. Of the cases, whose abnormal EEG improved in remission period, $83.3 \%$ were treated with anticonvulsants. In some bipolar cases, abnormal EEG is present from the onset of disease and it is associated with some clinical characteristics. Abnormal EEG returns to normal in half of the cases in remission period.
\end{abstract}

Keywords: first episode, mania, remission, EEG (electroencephalography)

\section{Introduction}

Data on BD (bipolar disorder) in epilepsy is more limited than that on depression. However, mood irregularity, mixed periods characterised by irritability and mania are more common in epilepsy than thought (Mula, Marotta, \& Monaco, 2010). Actually, epilepsy and BD shares some common characteristics. Both course in episodes and may become chronic. Triggering phenomenon, neurotransmitter irregularities,

Sermin Kesebir, M.D., associate professor, Erenköy Mental and Neurological Disease Training and Research Hospital. Sertaç Güven, M.D., Erenköy Mental and Neurological Disease Training and Research Hospital.

Elif Tatlıdil Yaylac1, M.D., Erenköy Mental and Neurological Disease Training and Research Hospital.

Özgür Bilgin Topçuoğlu, M.D., Erenköy Mental and Neurological Disease Training and Research Hospital.

Merih Altıntaş, M.D., Erenköy Mental and Neurological Disease Training and Research Hospital. 
irregularity in voltage gated ion channels, and irregularities in secondary messenger systems are similar changes suggested to play role in the etiology of both diseases. In addition, changes in $G$ proteins, phosphatidylinozitol, proteinkinase $\mathrm{C}$, and calcium activity have been described in both diseases. Common mechanism in ion channels is antikindling effects of antiepileptics regulating potassium outflux and antagonistic to calcium (Grunze, 2010).

In a study investigating epileptic phenomena in bipolar cases, in some cases with rapid cycles and positive family history, epileptiform activity characterised by bitemporal spike waves has been shown (Miller, Fox, Cohn, Forbes, Sherrill, \& Kovacs, 2002). In another study drawing attention to the relation between negative family history and abnormal EEG (electroencephalography), small sharp spikes were demonstrated in nearly half of these cases (Kano, Nakamura, \& Matsuoka, 1992). In some studies, relation was found between being refractory to treatment and some disorders in the form of sleep spindles detected in the awake EEG of some patients (Hudson, Lipinski, \& Frankenburg, 1988). In another study, in BD, temporal epileptic discharges and absence episodes correlating with episodic psychiatric symptoms in BD were found (Field \& Diego, 2008). In spite of all these findings, there is no specific and verified EEG finding for mania or BD, which can be disclosed with a rough visual analysis. Variations in EEG abnormalities reported in the literature and differing rates of EEG abnormalities reported may be accounted for by methodological differences. For mania, common results of qualitative EEG studies are dominant hemisphere dysfunction (Cook, Shukla, \& Hoff, 1986).

The aim of this study was to investigate the frequency of abnormal EEG findings in the first episode mania, determine whether EEG abnormality is resolved in the subsequent remission period, and compare the cases with or without EEG abnormalities in terms of clinical characteristics of BD.

\section{Method}

\section{Sample}

In the present study, 86 consecutive cases referring to our outpatient clinic or emergency service within the last year, who are between the ages of 18-65, whose informed consent form was signed by first degree relatives and were diagnosed with BD manic period according to DSM-IV and their first attack were included. Inclusion criteria were as follows: absence of previous depressive episode, absence of a neurological disease, especially epilepsy, and of head trauma or loss of consciousness, not using drugs which may affect electroencepholagraphical activity before recording of EEG (antiepileptics, naxiolytics, antideopressants, and antipsychotics). Previous depressive episodes obtained in eight patients. Some cases were excluded from the study $(n=6)$ as they had be administered a pharmacological agent that may influence EEG before EEG recording, some patients since their diagnosis was changed to schizoaffective disorder or psychotic disorder ( $n$ $=3$ ) and some others because they did not come to EEG recording in remission period $(n=7)$. Who did not come to EEG recording in remission period, they have not EEG abnormalities in manic episode. The data of remaining 62 patients were evaluated in the study.

\section{Tools}

SCID-I (DSM-IV Structured Clinical Interview). This form was developed by First, Spitzer, and Gibbon in 1997 in order to investigate first axis psychiatric disorders according to DSM-IV and its reliability and validity study in Turkish was carried out by Özkürkçügil, Aydemir, and Yıldız (1999).

SKIP-TURK (Mood Disorders Diagnosis and Follow-up Form). It was used to investigate 
sociodemographic and clinical characteristics of the patients (Özerdem, Yazıc1, \& Tunca, 2004).

YMRS (Young Mania Rating Scale). It was used to determine the severity of manic symptoms before treatment and to confirm the state of recovery. This form filled by interviewer was developed by Young, Biggs, Ziegler, and Meyer (1978) and its reliability and validity study in Turkish was carried out by Karadağ, Oral, and Yalçın (2001).

\section{Procedure}

Training and Research Hospital provided permission to conduct this study. YMRS was used in initial evaluation and in remission period. Following the diagnostic interviews (SCID-I), researchers initiated an open-ended interview with the BD patients relatives in order to complete the SKIP-TURK form. EEG of the cases was recorded prior to the onset of antimanic treatment. According to the severity of mania, in cases requiring sedation before EEG recording, haloperidol and quetiapine were preferred. The reason why they were preferred was that in the study of Centorrino et al. (2002) with 2,812 cases, haloperidol and quetiapine were established as the antipsyhotics with least effect on EEG activity. After manic episode EEG was recorded in each case, pharmacological treatment recommended by their own physician was commenced. In the present study, no intervention was made for mania treatment and investigators were blinded to treatment of mania. After remission was confirmed by YMRS (YMRS < 5) during at least two weeks, EEG recordings of remission period were made.

All EEG recordings were made in Erenkoy Mental and Neurologic Disease Training and Research Hospital EEG laboratory by the same EEG technician, using 33 channel ESAOATE, Mizar, 2004/Italy barcoded digital EEG device in 16 channels and, 23 surface electrodes were placed according to international 10-20 system. Recording electrodes are denoted by one letter or figure. Letter signifies the abbreviation of the region under the electrode: Prefrontal (FP), frontal (F), central (C), parietal (P), occipital (O), and auricular (A). Of the figures, odd numbers signify left side and even numbers the right side. Figures increase as distance from anterior posterior midline of the head increases (Fisch, 2008). EEG recordings were made at $70 \mathrm{~Hz}$ for 20 minutes with the eyes closed. At 5 th minute, hyperventilation was made for five minutes and at the 15 th minute, photic stimulation was made for three minutes.

It was determined: (1) whether EEG, was epileptic; and (2) if is not epileptic whether it involves other abnormal patterns (dysrhytmia, slow wave, amplitude abnormalities, and asymmetry).

\section{Statistical Analysis}

The comparison of numerical data was made with $T$-test and if they are not normally distributed with Mann Whitney-U test and comparison of categorical data was made using, Chi-square and Fisher Exact test. All tests were two ended and, $p$-value of less than 0.05 was considered significant. In order to determine predictive variables, regression analysis (forward) was used.

\section{Results}

\section{Sample}

Of cases in the first episode mania, $45.2 \%$ was female and $54.8 \%$ male and age of mean for 62 bipolar patients was $25.6 \pm 3.1$.

The frequency of epileptic and non-epileptic abnormal EEG in Mania and Remission. Among first 
attack bipolar cases, epileptic abnormal EEG was found in 2 cases (3.2\%), and non-epileptic abnormal EEG in 20 cases (32.3\%) (see Table1). Of cases with epileptic abnormal EEG, findings returned to normal in remission period in 1. Of 20 cases with non-epileptic abnormal EEG findings in manic episode, EEG returned to normal in remission period in $12(60 \%)$, while it persisted in eight cases $(40 \%)$. Epileptic or non-epileptic EEG abnormality was more frequent in mania than remission $\left(p=0.022, x^{2}=11.326\right)$.

Table1

The Frequency of Epileptic and Non-epileptic Abnormal EEG in Mania and Remission

\begin{tabular}{llll}
\hline & $\begin{array}{l}\text { Mania } \\
(n=62)\end{array}$ & $\begin{array}{l}\text { Remission } \\
(n=62)\end{array}$ & $\begin{array}{l}\text { Analysis } \\
x^{2} ; p\end{array}$ \\
\hline Normal EEG & 40 & 53 & \\
Epileptic EEG & 2 & 1 & $11.326 ; 0.022$ \\
Non-epileptic abnormal EEG & 20 & 8 & \\
\hline
\end{tabular}

Comparison of cases with and without abnormal EEG in First Episode Mania. In first episode mania, abnormal EEG was more frequent in female sex $\left(15 / 5\right.$ and 15/27) $\left(p=0.003, x^{2}=7.064\right)$. Mean of age was similar between bipolar patients with and without abnormal EEG (25.8 \pm 13.7 vs. $24.5 \pm 9.3)$.

Mode and complications of delivery, history of febrile convulsion was not different between two groups. Age of menarche is similar between two groups $(13.8 \pm 1.2$ vs. $13.9 \pm 1.2)$. Comorbid physical disease is present in all cases with abnormal EEG $\left(20 / 0\right.$ and 14/28) $\left(p<0.001, x^{2}=25.132\right)$. These comorbid physical disease were diabetes and hypertension.

Childhood trauma was found to be more frequent (physical and/or sexual abuse) in BD cases with abnormal EEG than those without abnormal EEG $\left(16 / 4\right.$ and 18/24) $\left(p=0.001, x^{2}=12.916\right)$. Likewise, in those with childhood psychiatric disease history, abnormal EEG were more frequent than those without such history $\left(14 / 6\right.$ and 16/26) $\left(p=0.005, x^{2}=10.649\right)$ (see Table 2). These diagnosis include ADHS, learning difficulty, enuresis and separation anxiety. No difference was found between BD cases with abnormal EEG and those without abnormal EEG with respect to family history. History of suicide attempt was found to be more frequent in BD cases with abnormal EEG (3/11 and 3/44) $\left(p=0.005, x^{2}=8.176\right)$.

Table 2

Comparison of Cases With and Without Abnormal EEG in Remission

\begin{tabular}{llcc}
\hline & $\begin{array}{l}\text { With abnormal EEG } \\
(n=8)\end{array}$ & $\begin{array}{l}\text { Without abnormal EEG } \\
(n=12)\end{array}$ & $\begin{array}{l}\text { Analysis } \\
x^{2} / t ; p\end{array}$ \\
\hline Gender (F/M) & $8 / 0$ & $2 / 10$ & $11.235 ; 0.001$ \\
Age (Mean \pm SD) & $30.8 \pm 14.1$ & $28.3 \pm 11.5$ & $0.500 ; 0.590$ \\
Age of menarche (Mean \pm SD) & $13.1 \pm 0.8$ & $14.8 \pm 0.9$ & $0.300 ; 0.032$ \\
Childhood trauma (physical or sexual abuse) (\%) & 100 & 16.6 & $14.825 ; 0.001$ \\
Childhood psychiatric diagnosis history (\%) & 75 & 83.3 & $1.095 ; 0.232$ \\
Family history (\%) & 12,5 & 66.6 & $6.730 ; 0.008$ \\
Psychotic finding (\%) & 50 & 66.6 & $1.447 ; 0.748$ \\
Suicide attempt (\%) & 50 & 25 & $1.270 ; 0.050$ \\
\hline
\end{tabular}

The frequency of psychotic findings and YMRS scores were similar between two groups $(27.4 \pm 4.1 \mathrm{vs}$. $28.5 \pm 4.9)$.

Predictors of abnormal EEG in the first episode Mania. Childhood trauma was found to be predictor of EEG abnormality in first episode mania cases with regression analysis. In other words, childhood trauma 
increased the risk of abnormal EEG in first episode BD cases by 10.8 fold (CI 95\% 1.8-4.9, $p=0.004$ ).

Comparison of cases with and without abnormal EEG in Remission. All of the cases who have continuing abnormal EEG findings in remission period are women (8/0 vs. 2/10) (see Table 2). Mean of age is similar in both groups $(30.8 \pm 14.1 v s .28 .3 \pm 11.5)$.

Except for age of menarche in the groups with abnormal EEG $(13.1 \pm 0.8 v s .14 .8 \pm 0.9)(p<0.032, t=$ 4.1), mode and complications of delivery, febrile convulsion history and comorbid physical disease were similar between the groups (see Table 2). Family history was found to be more common in the group whose without abnormal EEG $(1 / 7$ and $8 / 4)\left(p=0.008, x^{2}=1.130\right)$. Childhood trauma was present all cases with abnormal EEG while childhood history of psychiatric disease was found to be similar between those with and without abnormal EEG. Family history of suicide attempt was more frequent among cases with abnormal EEG $(4 / 4$ and $3 / 9)\left(p=0.005, x^{2}=1.270\right)$.

\section{Antimanic Treatment in Cases}

In the present study, antimanic treatment of first attack mania cases, was not controlled for. In the retrospective evaluation of these data, to which the investigators were blinded, it was found that the rate of anticonvulsant use was $83.3 \%(n=10)$ in cases without abnormal EEG findings in remission period while there was no anticonvulsant use in cases with continuing abnormal findings.

\section{Discussion}

The rates of abnormal EEG in the present study, among bipolar cases in first episode mania, were found 23.9\%. These rates are similar to those reported by other authors (Cook, Shukla, \& Hoff, 1986; Small, Milstein, \& Medlock, 1997). The fact that our cases were first episode ones demonstrate that in BD, EEG abnormality is present form the onset of the disease in some cases. According to our results, EEG abnormality detected in mania continues in some cases during remission period while it returns to normal in some other cases. Namely, in some bipolar cases, EEG abnormality emerges during mania. In cases, with continuing EEG abnormality in remission period, if we consider this a phenomenon independent of mania (trait), in cases whose EEG abnormality is finished, this may be regarded as specific to mania (state). In cases with continuing abnormal EEG, to understand whether this phenomenon independent of mania is an endphenotype requires comparison with healthy controls and healthy first-degree relatives of the bipolar cases and should be investigated by further studies.

In the present study, the emergence of EEG abnormality during mania and its disappearance with the end of mania in some bipolar cases disproves the previous claim that EEG may be used to distinguish primary mood disorders from secondary ones (Cook et al., 1986). In contrast, the relation of EEG abnormality with many variables makes it necessary to determine whether it is secondary to mania. Actually, in the present study, the influence of many clinical variables such as sex and age of menarche, family history, childhood trauma, and history of psychiatric diagnosis in childhood on EEG was demonstrated. In addition, comorbid physical disease was present in all cases with EEG abnormality. The physical diseases were diabetes and hypertension. While there is no EEG abnormality linked to hypertension, EEG abnormality in some individuals without any psychiatric disorder was linked to diabetes. In this relation, slow wave intensity was found to be associated with the number of glicemic attacks. While there is no case of EEG abnormality linked to hypertension in the literature, in individuals without any psychiatric disease EEG abnormality was found to be associated with diabetes (Brismar, 2007). Present information underscores the fact that the findings of electrophysiological 
studies should be cautiously interpreted.

In the present study, the history of childhood psychiatric disease was found to be more common in cases with abnormal EEG than those without abnormal EEG. However, this difference found in manic period was not found between cases whose abnormal findings persisted in recovery period and those whose abnormal findings disappeared. The diagnosis of childhood psychiatric disease history is ADHD, learning difficulty, enuresis, and separation anxiety. ADHS, learning difficulty and enuresis may lead to EEG abnormality. Actually, in children diagnosed with ADHS, the history of seizure was found at the rate of 8\%, and abnormal EEG finding at $15.5 \%$ (Cornelio-Nieto, Borbolla-Sala, \& Gallegos-Dimas, 2011). EEG abnormality in ADHS is related to inhibition control disorder (Hale et al., 2010). In one fourth of children with enuresis nocturna it was been (Kawauchi, Imada, Tanaka, Minami, Watanabe, \& Shirakawa, 1998). EEG abnormalities may arise in many learning difficulties, particularly dyslexia (McArthur, Atkinson, \& Ellis, 2009). Learning difficulty is associated with Gama activation in parietal, frontoparietal and temporal regions and correlates with impulsivity scores for the distractibility of attention (DePascalis, Varriale, \& Rotonda 2011).

EEG abnormality detected during first attack mania seems not to be related to the severity of mania, since in mania no difference was found between cases with EEG abnormality and those without it and between cases whose EEG abnormality continued in recovery period and those in whom it disappeared, in terms of YMRS scores. Consitent with this, the frequency of psyhotic findings was found to be similar between cases who are with and without EEG abnormality in mania and recovery.

One of the variables linked to EEG abnormality in bipolar disease is family history. In the study of Small, Milstein, and Medlock in 1997 with a relatively large sample, a significant relation was found between moderate and severe EEG abnormality and negative family history. A similar result was obtained by Cook et al (1986) in a sample of 46 subjects. In the study of Vaaler, Morken, Iversen, Kondziella, and Linaker (2010) epileptic form activity was found to be more frequent in the group with family history. In the present study, no difference was found between bipolar cases with abnormal EEG findings and those without them with regard to family history. However, when evaluation is made separately in first degree and second degree relatives, it was seen that family history in first degree relatives was present in $70 \%$ of cases with EEG abnormality. Family history was found to be more frequent in bipolar cases whose abnormal findings stopped in recovery period than those in whom abnormality continued. In other words, in cases with EEG abnormality secondary to mania, family history was found to be more common than cases in whom there was trait EEG abnormality. Our findings support the relation between trait EEG abnormality and negative family history and are congruent with those of Cook et al. (1986) and Small et al. (1997).

Childhood traumas have a high prevalence in $\mathrm{BD}$ and strong relation is present between physical abuse and mania (Levitan, Parikh, Lesage, Hegadoren, Adams, Kennedy, \& Goering, 1998). In the present study, childhood trauma was found to be more common in cases which had EEG abnormality in manic period which continued in remission period. In addition, it was found to be a predictor of EEG abnormality in first attack bipolar cases, which is not an unexpected result, because childhood traumas affect neurobiological development of the brain by changing BDNF levels and stress responses (Etain, Henry, Bellivier, Mathieu, \& Leboyer, 2008). Cook et al. (2009) compared in three groups, i.e., those with childhood trauma, those with stress disorder after trauma, and those without stress disorder and, showed that childhood trauma group had EEG coherence in all central, frontal, temporal and parietal areas, which is seen as evidence for long term effect of childhood traumas on neural connectivity. 
Common point between suicide attempt and mania is impulsiveness. Its finding in EEG is Gama activation in parietal, frontoparietal, and temporal regions (Logemann, Lansbergen, Van Os, Böcker, \& Kenemans, 2011). In the present study, the family history of suicide attempt was found to be more frequent in bipolar cases which had abnormal EEG findings in manic period, which continued in remission period. Therefore, suicide attempt and EEG abnormality are associated irrespective of the presence of mood episode. Another relation between suicide attempt, BD and abnormal EEG findings may be established through childhood traumas. In many studies, suicide attempt occurs at higher rates in bipolar cases with childhood trauma (Lim, Song, Hwang, Lee, Suh, Park, \& Kwon, 2010). Drawing upon these findings, it can be suggested that in psychiatric disorders in general and in BPD in particular, the mediator between suicide and epilepsy is childhood trauma.

According to our findings, abnormal EEG findings are preponderant in female cases both in first attack mania and in recovery period. In other words, the reflection of mood disorder on EEG seems to be more explicit in women. This can be interpreted with the relation between female sex and childhood trauma. Abuse occurs more commonly in female sex (Levitan et al., 1998) and the impact of childhood traumas on HPA (hypothalamopituiter adrenal axis) function is more marked in women (DeSantis, Beker, Back, Spratt, Ciolino, Moran, Diparkar, \& Brady, 2011).

Perimenarche was reported to a risk factor for appearance or deterioration of epilepsy in 2003. Following studies did not confirm this finding and reported that the risk of emergence of epilepsy was higher in 10-18 age range than 0-9 age range, and this is not associated with menarche (Dworetzky, Townsend, \& Pennell, 2012). In the present study, in cases with trait EEG abnormality, the age of menarche was found to start at a younger age. In a more recent study, it was reported that in early puberty, EEG spectral power intensity changed developmentally and maturation occurred at different rates in both sexes (Cragg, Kovacevic, McIntosh, Poulsen, Martinu, Leonard, \& Paus, 2011). According to the results of this prospective study, if compared in terms of EEG, female sex has a developmental delay interval. In the brain exposed to increasing gonadal hormone levels increasing with puberty relatively early before maturation process is completed, some traces may be left.

In the present study, antimanic treatment of first attack mania cases, was not controlled for. In the retrospective evaluation of these data, to which the investigators were blinded, it was found that the rate of anticonvulsant use was $83.3 \%$ in cases without abnormal EEG findings in remission period while there was no anticonvulsant use in cases with continuing abnormal findings. Based upon this finding, it was thought that it would be reasonable to recommend anticonvulsant use in BD cases with EEG abnormality. It was also investigated whether EEG recorded before initiation of drug would predict the response to treatment with antipsyhotics, but no results were obtained in this regard (Reeves, Burke, \& Struve, 2011).

\section{References}

Brismar, T. (2007). EEG physiological and clinical studies. Physiol. Behav., 92, 141-147.

Centorrino, F., Price, B., Tuttle, M., Bahk, W. M., Hennen, J., Albert, M. J., \& Baldessarini, R. J. (2002). EEG abnormalities during treatment with typical and atypical antipsychotics. Am. J. Psychiatry, 159, 109-115.

Cook, B. L., Shukla, S., \& Hoff, A. L. (1986). EEG abnormalities in bipolar affective disorder. J. Affect Disord., 11, 147-149.

Cook, F., Ciorciari, J., Varker, T., \& Devilly, G. J. (2009). Changes in long term neural connectivity following psychological trauma. Clin. Neurophysiol, 120, 309-314.

Cornelio-Nieto, J. O., Borbolla-Sala, M. E., \& Gallegos-Dimas, A. (2011). Electroencephalographic alternations in children with attention deficity hyperactivity disorder. Rev. Neurol., 1, 97-101.

Cragg, L., Kovacevic, N., McIntosh, A. R., Poulsen, C., Martinu, K., Leonard, G., \& Paus, T. (2011). Maturation of EEG power spectra in early adolescence: A longitudinal study. Dev. Sci., 14, 935-943. 
DePaskalis, V., Varriale, V., \& Rotonda, M. (2011). EEG in a learning tasks: Effect of attentional impulsivity and learning ability. Int. J. Psychophysiol, 8, 11-20.

DeSantis, H., Beker, N. L., Back, S. E., Spratt, E., Ciolino, J. D., Moran, M., Diparkar, B., \& Brady, K. T. (2011). Gender difference in the effect of early trauma on HPA functioning. Depress Anxiety, 28, 383-392.

Dworetzky, B. A., Townsend, M. K., \& Pennell, P. B. (2012). Female reproductive factors and risk of seizure or epilepsy. Epilepsia, 53(1), 1-4.

Etain, B., Henry, C., Bellivier, F., Mathieu, F., \& Leboyer, M. (2008). Beyond genetics: Childhood affective trauma in bipolar disorder. Bipolar Disord., 10, 867-876.

Field, T., \& Diego, M. (2008). Maternal depression effects on infant frontal EEG asymmetry. Int. J. Neurosci, 118, $1081-1108$.

First, M. B., Spitzer, R. L., \& Gibbon, M. (1997). Structured clinical interview for DSM-IV clinical version (SCID-I/CV). Washington D.C., American Psychiatric Press.

Fisch, B. J. (2008). Fisch ve Spehlmann'dan EEG'ye Giriş: Dijital ve Analog EEG'nin Temel İkeleri. 3. Baskı. Şahiner T (Çev. ed). (Basic EEG from Fisch and Spehlmann: Fundamentals of digital and analog EEG (3rd ed.)). İstanbul, Turgut Yayıncılık.

Garno, J. L., Gunawardane, N., \& Goldberg, J. F. (2008). Predictors of trait aggression in bipolar disorder. Bipolar Disord., 10, 285-292.

Grunze, H. C. (2010). Anticonvulsants in bipolar disorder. J. Ment. Health, 19, 127-141.

Hale, T. S., Smalley, S. L., Walshaw, P. D., Hanada, G., Macion, J., McCracken, J. T., McGough, J. J., \& Loo, S. K. (2010). Atypical EEG beta asymmetry in adults with ADHD. Neuropsychologia, 48(12), 3532-3539.

Hudson, J. I., Lipinski, J. R., \& Frankenburg, F. R. (1988). Electroencephalography in mania. Arch. Gen. Psychiatry, 45, $267-273$.

Kano, K., Nakamura, M., \& Matsuoka, T. (1992). The topographical features of EEGs in patients with affective disorders. Electroencephalogr Clin. Neurophysiol, 83, 124-129.

Karadağ, F., Oral, E. T., \& Yalçın, F. (2001). Young Mani Derecelendirme Ölçeği’nin Türkiye'de geçerlik ve güvenirliği (Young mania rating scale reliability and validity of Turkish version). Türk Psikiyatri Dergisi, 13, 107-114.

Kawauchi, A., Imada, N., Tanaka, Y., Minami, M., Watanabe, H., \& Shirakawa, S. (1998). Changes in the structure of sleep spindles and delta waves on electroencephalography in patients with nocturnal enuresis. Br. J. Urol., 3, 72-75.

Klein, P., Van Passel Clark, L. M., \& Pezzullo, J. C. (2003). Onset of epilepsy at the time of menarche. Neurol., 60, 495-497.

Levitan, R. D., Parikh, S. V., Lesage, A. D., Hegadoren, K. M., Adams, M., Kennedy, S. H., \& Goering, P. N. (1998). MD in individuals with history of childhood abuse: Relationship to mania and gender. Am. J. Psychiatry, 155, 1746-1752.

Lim, H. W., Song, H. S., Hwang, Y. H., Lee, H. W., Suh, C. K., Park, S. P., \& Kwon, S. H. (2010). Predictors of suicidal ideation in people with epilepsy living in Korea. J. Clin. Neurol., 6, 81-88.

Logemann, H. N., Lansbergen, M. M., Van Os, T. W., Böcker, K. B., \& Kenemans, J. L. (2010). The effectiveness of EEG-feedback on attention, impulsivity and EEG: A sham feedback controlled study. Neurosci Lett, 479(1), 49-53.

McArthur, G., Atkinson, C., \& Ellis, D. (2009). Atypical brain responses to sounds in children with specific language and reading impairments. Dev. Sci., 12(5), 768-783.

Miller, A., Fox, N. A., Cohn, J. F., Forbes, E. E., Sherrill, J. T., \& Kovacs, M. (2002). Regional patterns of brain activity in adults with a history of childhood-onset depression: gender differences and clinical variability. Am. J. Psychiatry, 159, 934-940.

Mula, M., Marotta, A. E., \& Monaco, F. (2010). Epilepsy and bipolar disorders. Expert Rev. Neurother, 10, 13-23.

Özerdem, A., Yazıc1, O., \& Tunca, Z. (2004). Mood disorders study group, psychiatric association of Turkey and K T1rpan: Establishment of computerized registry program for bipolar illness in Turkey: SKİ-TÜRK. J. Affect Disord., 84(1-2), 82-86.

Özkürkçügil, A., Aydemir, Ö., \& Yıldız, M. (1999). DSM-IV Eksen I bozuklukları için yapılandırılmış klinik görüşmenin Türkçe'ye uyarlanması ve güvenilirlik çalışması (Structured clinical interview DSM-IV for Axis I disorders: Translation and reliability study). İlaç ve Tedavi Dergisi, 12, 233-236.

Reeves, R. R., Burke, R. S., \& Struve, F. A. (2011). EEG does not predict response of manic patients to atypical antipsichotics. Clin. EEG Neurosci, 42, 25-32.

Small, J. G., Milstein, V., \& Medlock, C. E. (1997). Clinical EEG findings in mania. Clin. Electroencephalogr, 28, $229-235$.

Vaaler, A. E., Morken, G., Iversen, V. C., Kondziella, D., \& Linaker, O. M. (2010). Acute unstable depressive syndrome (AUDS) is associated more frequently with epilepsy than major depression. BMC Neurol., 10, 67.

Young, R. C., Biggs, J. T., Ziegler, V. E., \& Meyer, D. A. (1978). A rating scale for mania: Reliability, validity and sensitivity. $B r$. J. Psychiatry, 133, 429-435. 